\title{
Correlates of Principals Attachment Styles, Leadership Styles and Principals' Effectiveness: The Case of Secondary Schools in Ethiopia
}

\author{
Dr. SOLOMON LEMMA LODISSO \\ Associate Professor, Department of Educational Planning and Management, Hawassa University
}

\begin{abstract}
The purpose of this study was to assess the relationship between attachment style, leadership styles and perceived leaderships effectiveness in government secondary schools in Ethiopia. Survey research design was used. Seventeen schools were selected randomly. Using Yamana's (1967) formula 209 teachers were selected from sample schools proportionally using systematic random sampling technique. The Relationship Questionnaire (RQ) for attachment style and The Multifactor Leadership Questionnaire (MLQ) were used to measure leadership style and leaders' effectiveness. The research findings indicated that there is statistically significant relationship between transformational leadership and secure; Positive weak relationship was observed between preoccupied and transactional; Fearful attachment behavior of the leader is also moderately correlates with laissez-faire leadership style; there was a significantly moderate relationship between principals' effectiveness and secure attachment style. It was also found that there was positive but moderate level of relationship between leadership style and overall attachment styles and strong correlation between attachment styles and leadership style with perceived leadership effectiveness. A regression analysis result indicated that the four attachment style statistically significant predictor of leadership styles (transformational, transactional and laissez-faire) even if the predictive power is low. It is also recommended that future research could do similar study using a different population in different setting, with different leadership style and different type of attachment styles to determine if the findings are reliable.
\end{abstract}

Keywords: Attachment style, leadership style, principal's effectiveness, transformational, transactional and laissez-faire.

DOI: $10.7176 /$ RHSS/10-7-02

Publication date: April $30^{\text {th }} 2020$

\section{INTRODUCTION}

The performance of an organization positively related to Leadership effectiveness. If an organization wants to improve its performance, it is the leadership effectiveness that should be analyzed and adapted to new requirements. School principal effectiveness is the positive response to administrative efforts and actions with the intention to accomplish stated goal. His/her performance in decision making, delegation of duties to subordinates, communication and setting good examples and motivating the teachers and students alike in an effort to create a conducive working environment to accomplish school goal and objective seem to enhance subordinate performance for school success (Adegun, 2002). Effective principals are liked and respected, rather than feared, and communicate caring for students as well as willingness to impose punishment if necessary (Tess, 2003). Thus, it is critical that we have to have a comprehensive understanding of the personal variables that contribute to effective leadership.

Effective leadership is sometimes difficult to define since it is built upon many variables and characteristics influencing the way it is measured in order to be considered effective (POPA, 2012). One of the influencing variables is the leader's attachment style. Attachment theory inspired researchers to understand leader-follower relations from a new angle. Different researchers (Keller 2003; Breshanan and Mitroff 2007), links attachment styles and childhood experiences with leaders' perceptions and performances. This is due to the fact that attachment style is an antecedent of leadership practice in which attachment relationships are formed with individuals that one is close to and who can encourage and support in new situations or experiences (Fraley and Shaver, 2000).

According to Ainsworth, Blehar, Waters, and Wall (1978), the attachment experiences developed at individuals early experiences with their own caregiver led an individual to develop different attachment style to other individuals. These styles, in turn may influence the individuals interactions with others. Therefore, the attachment style of leaders can influence their choice of leadership styles.

Attachment style defined by Ainsworth, Blehar, Waters, and Wall (1978) as a ways in which one relates to others and is based on early experiences with caregivers. According to Bowlby, (1988) the basis of the baby's primary experience and an internal working model is formed by constitutes of mental representation of the self, of significant others, and of the child's relations with them. This internal representation forms the basis for later representations of the self and the world, and guides one's interactions with others. Therefore, the attachment style 
of the leaders determines their choice of leadership style based on Bowlby's theories.

Bartholomew and Horowity, (1991) identified four different attachment styles: secure, preoccupied, dismissing and fearful. It was reported that people with a secure attachment style display high levels of warmth and balance of control. They argue that leaders with dismissing attachment style are self confident but are low in emotional expression. Leaders with preoccupied attachment style display extreme anger and discomfort in friendship. Lastly, leaders with fearful attachment style exhibit low self confidence, self image and balance of control. Dismissal, preoccupied and fearful attachment styles are collectively referred to as insecure attachment style.

Doverspike, Hottis, Justicee and Polomsky (1997), also indicated that secure attachment has been associated with a rational (as opposed to task-oriented) and also avoidant attachment was associated with a tendency towards task-oriented leadership. In their study secure attachment style fosters exploration and support. In another study, Johnston (2000) demonstrated that leaders with secure attachment style are more likely to delegate while avoidant leaders practice the least amount of delegation.

Early researchers were mostly interested in individual differences and they tried to identify the relation between different attachment styles (security, anxiety, and avoidance) and leader and their leadership style. Recent researchers (eg. Mayseless 2007; Keller and Cacioppe 2001) were interested in assessing the attachment orientation of leaders and followers, the role of moderating and mediating variables and the provision of support and care by the leaders.

In their study Popper and Mayseless (2003) have found that transformational leaders tend to have a secure attachment style. Similar research (e.g., Bass, 1985; Popper et al., 2000) has also shown a positive relationship between charismatic leadership and secure attachment. Other research outputs indicated that different attachment style relates to different leadership styles. For example, transformational leadership style was closely linked with secure attachment and Laissez-faire with avoidant attachment style, and avoidant/dismissing attachment was negatively associated with transformational leadership style (Davidovity, etal 2007). Another study conducted in Australia (de Sanctis and Kareantzas, 2008) found that securely attached leaders were described by their followers as being more effective than insecurely attached leaders.

Most recent researches (Welch \& Houser, 2010) have shown that individuals with an insecure attachment style have difficulty in maintaining high levels of hope and are unable to work effectively with others. It was also reported that there is strong correlation between secure attachment style and transformational leadership style (Berson \& Yammarino, 2006; Popper, et al., 2000). Similarly, Popper et al., (2003) reported that transformational leaders with a secure attachment style were more available to their followers through giving, encouraging, and empowering in leadership relations compared to leaders with an insecure attachment style (fearful, dismissing, preoccupied).

A study conducted with Israeli officers reported that leaders with anxious attachment orientation were described by their followers as having lower task performance and leaders with avoidant style were reported as having lower emotional experiences. It was also reported that leaders with avoidant style were described as being less cohesive (Davidovity, Mikulincer, Shaver, Izsak and Popper 2007). They also found that leaders with insecure attachment style as reported by their follower are associated with poor performance. Early research in this area reported that most leaders tend to have a secure attachment style which is positively related with leadership styles (like transformational, charismatic and relation oriented leadership). It was also reported that leaders' effectiveness and positive outcome was associated with leaders' secure attachment style (Kafetsios, Athanasiadou and Dimou 2014). Kafetsios, Athanasiadou and Dimou (2014) also reported that leaders in organization who exhibit anxious attachment style, led subordinate to have lower positive affect and job satisfaction. In support of this point Ronen and Mikulincer (2012) stated that leaders with in secure attachment style were associated with followers' turnover and job dissatisfaction while leaders with ineffective caring style mediated this relation.

Research findings (e.g., Bass, 1985; Popper, 2014) have underscored the importance of individual consideration leadership style from the leaders where their provision of care and support increase workers trust. Though many leadership styles and theories have been identified, the most effective leaders are characterized by communicating their vision, being friendly, willing to support and care for followers and taking risk (Amneric, Craig and Tourish 2007). All these characteristics are related with transformational and charismatic leadership style (Barrick and Mount 1991; de Hoogh et al, 2005).

Recent research has also reported that transformational and charismatic leadership styles are associated with followers' commitment, job satisfaction, organizational commitment and motivation (Avolio, Routundo and Wulumbwa 2009). Conversely, Padilla, Hogan and Kaiser 2007; and Tepper, 2000) reported that laissez-faire leadership negatively correlates with follower psychological wellbeing, job performance and productivity and positively with higher turnover of the workers.

As previous research indicated, different leadership styles were identified and transformational, charismatic and servant leaders were perceived by subordinates as trustworthy and compassionate (Jandaghi et al., 2009), which, in turn, leads to overall positive subordinate outcomes (Dadhich \& Bhal, 2008; Jaramillo, Grisaffe, Chonko, 
\& Roberts, 2009). It was also reported by (Aryee, Sun, Chen, \& Debrah, 2007; Skogstad, Einarsen, Torhsheim, Aasland \& Hetland, 2007) that Laissez-faire leadership style tends to positively relates with negative perceptions of leadership behavior by subordinates.

Even though, there are some researchers (e.g., Mikulincer \& Florian, 1995; Popper, Mayseless and Castenovo 2006) who assessed the relationship between leader's attachment style and leadership style, there is limited research on attachment style (secure attachment) and leadership style (transformational leadership).

To the knowledge of the researcher to date, there is limited information on the relationship between different leadership styles to the different styles of attachment (secure, fearful, dismissing, and preoccupied). Therefore, the purpose of this study was to determine which attachment style(s) relate with different leadership styles. In doing so, this study explores how the four different styles of attachment relate to various leadership styles.

\section{Objectives of the study General Objective:}

The purpose of this study was to assess whether attachment style(s) relate to different leadership styles and leaders effectiveness as perceived by their teachers

\section{Specific Objectives}

Specifically, the research will try to meet the following specific objectives

- To examine the relationship among principals attachment style, leadership style and principals effectiveness

- To identify attachment styles that strongly determine principals' leadership style in secondary schools

- To examine which attachment style best predicts leaders' effectiveness as perceived by teachers.

\section{Research questions}

1. Is there a relationship between principals' attachment style, leadership style and principals' perceived effectiveness?

2. Which attachment style(s) strongly relate to principals leadership style in secondary school of HU catchment area

3. Which attachment style best predicts principals' effectiveness as perceived by secondary school teachers?

\section{MATERIALS AND METHODS}

The study was conducted in the secondary schools located in Hawassa University (HU) community service mandate area. The catchment of Hawassa University comprises six woredas (districts) in Sidama Zone and Hawassa City Administration. Data were collected from all the six woreda and Hawassa City Administration. The study participants were secondary school teachers.

The survey research design was used. This design was selected because correlation design used to describe and measure the degree of association (or relationship) between two or more variables and predict an outcome (Kothari 2015).

From government secondary schools found in the HU catchment area $17(60 \%)$ schools were selected randomly. The sample size for the teachers in these schools was computed using Yemane's (1967) formula. The tolerable errors is 0.05 with $95 \%$ confidence about being right derived from the population using (Yamane, 1967) statistical formula.

$$
\mathrm{n}=\frac{\mathrm{N}}{1+N(\mathrm{e}) 2}
$$

Where; ' $\mathrm{n}$ ' is expected sample size, ' $\mathrm{N}$ ' is the size of the target population and 'ê' is margin error (0.05). Using this formula 209 teachers were selected from sample schools proportionally using systematic random sampling technique.

\section{Instruments used for data collection Attachment style} Attachment style was measured using The Relationship Questionnaire (RQ: Bartholomew \& Shaver, 1998). In the questionnaire four components were indicated to measure leaders attachment style (secure, dismissing preoccupied, and fearful) using a 5-point Likert-type scale from 1 (not all like him) to 5 (very much like him). The wordings of the questions were modified slightly to accommodate the target population. The reliability of the RQ was reported (Bartholomew \& Horowitz, 1991), with alpha coefficients ranging from .87 to .95 and the reliability of the current adapted instrument was .89 which is considered good.

Leadership styles questionnaire:

The Multifactor Leadership Questionnaire (MLQ), Form 5X-Short (Bass, 1985) was used to measure Leadership 
styles and effectiveness. According to Avolio \& Bass, (2004) and Bass \& Avolio, (2000), the MLQ used to measure three major leadership styles: transformational, transactional, laissez-faire, as well as instructor perceptions of leader effectiveness. The MLQ asks participants to provide ratings for self and for others. In this study, teachers, who are not in leadership positions were asked to rate their principals. Participants were asked to evaluate how frequently their leader uses the leadership style in a given situation. $(1=$ Not at all; $2=$ Once in a while; $3=$ Sometimes; $4=$ fairly often; and 5=frequently if not always). The internal consistency reliability of MLQ was reported Chronbach's alpha reliability range from .67 to .94 across studies (Heinitz, Liepmann, \& Felfe, 2005, Sadeghi \& Lope Pihie, 2012). Similarly, the reliability of the adapted instrument was also checked (See Table 1) and it was found .79 to .91 which is considered good.

\section{Results}

\section{Rate of return of the questionnaire and Reliability of the instruments}

From the total of 209 questionnaires distributed, to secondary school teachers in the HU community service catchment area, 198 (94.8\%) questionnaires were returned and found usable. This return rate was considered good as compared to the previous studies. The Reliabilities, Means, and standard deviations for subscales and composites for each of these scales are given in Table 1. The reliabilities were found between .79 up to .91 which is considered good.

Table 1: Reliability, Means, and SDs for all Scale Variables, $\mathrm{N}=198$.

\begin{tabular}{llll}
\hline Scale Name & Reliability & Mean & SD \\
Attachment & .79 & 3.73 & 1.15 \\
Effectiveness & .91 & 4.97 & 1.03 \\
Transformational & .87 & 3.17 & 1.50 \\
Transactional & .88 & 3.04 & 1.60 \\
Laissez-faire & .89 & 2.99 & 1.64 \\
\hline
\end{tabular}

\section{Demographic analysis}

Demographic data were analyzed using descriptive statistics. According to Trochim, (2006), the purpose of descriptive statistics is to describe the main features of the data, the sample and the measures. Accordingly, the majority $115(\%)$ are male, $118(\%)$ with first degree and $7(\%)$ have served $6-10$ years.

Table 2: Demographic characteristics of the respondents

\begin{tabular}{lllll}
\hline no & Item & frequency & $\%$ \\
1 & Gender & male & 115 & 58.1 \\
& & female & 83 & 41.9 \\
2 & Educational status & diploma & 16 & 8.1 \\
& & First degree & 118 & 59.6 \\
& & Second deg & 64 & 32.3 \\
3 & Service year & $1-5$ & 33 & 16.6 \\
& & $6-10$ & 76 & 38.4 \\
& & $11-15$ & 50 & 25.3 \\
& & $16-20$ & 8 & 4.0 \\
& & Above 20 & 31 & 15.7 \\
\hline
\end{tabular}

\section{Correlations between Attachment Styles, Leadership Styles and leader's effectiveness}

The following table depicts the relation between attachment styles, leadership styles and leaders' effectiveness as perceived by the teachers using Spearman rho correlation. Correlation testing began after data were assessed to ensure assumptions for Spearman's rho were met, which included testing of ordinal data and a monotonic relationship between the variables (Morgan, 2004). Verification of a monotonic relationship was confirmed through visual examination of scatter plots. The assumption addressing ordinal data was met through the type of data gathered from The Relationship Questionnaire (RQ) and Multifactor Leadership Questionnaire (MLQ) Likert scale surveys (Tabachnick \& Fidell, 2007).

The value of correlation coefficient ( $r$ ) indicates the direction and the strength of the relation of the variables. Different researchers use different descriptors for the ranges of $r$ value. Even though the choice of label depends on the data, the context of the scientific argument and the investigator's temperament, Evans (1996) suggests the following helpful guide of arbitrary labels for ranges of $r$ values: \pm .80 to 1.00 as very strong, \pm .60 to .79 strong, \pm .40 to .59 moderate, \pm .20 to .39 weak and. \pm OO to .19 very weak. 
Table 3: Correlations between Attachment and Leadership Styles and principals" effectiveness (N=198)

\begin{tabular}{lllll}
\hline & secure & preoccupied & Dismissing & fearful \\
transformational & $.380^{* *}$ & $.194^{* *}$ & $.471^{* *}$ & -.039 \\
transactional & $.235^{* *}$ & -.084 & $.622^{* *}$ & $.286^{* *}$ \\
Laissez faire & $-146^{*}$ & .126 & $.488^{*}$ & $.589^{* *}$ \\
effectiveness & $.231^{*}$ & -152 & -071 & .137 \\
\hline
\end{tabular}

*significant at $\mathrm{p}<.05, * *$ significant at $\mathrm{p}<.01$

The relation between leadership styles and attachment was assessed using spearman's rho correlation and the results of the correlation analysis indicated that there is statistically significant relationship between transformational leadership and secure, preoccupied and dismissing attachment style, $(r=.380)$, Preoccupied $(r=$ $194)$ and dismissing $(\mathrm{r}=.471)$ attachment style with $\mathrm{P}<.000$ respectively. The relationship was however weak for secure and preoccupied attachment styles; and moderate for dismissing attachment style. On the other hands, transformational leadership style and fearful attachment style have no correlation, $\mathrm{r}=-.039, \mathrm{n}=198, \mathrm{P}<.005$.

The coefficient of determination (R-square) between transformational leadership and dismissing attachment style is .2218 , meaning, $22.2 \%$ of the variance of in transformational leadership can be explained by dismissing attachment style. The coefficient of determination between transformational leadership style and secure attachment style is .1444; meaning $14.4 \%$ of the variance of in transformational leadership style can be explained by secure attachment style.

There was a weak correlation between secure $(\mathrm{r}=.235, \mathrm{p}<.005)$ and fearful $(\mathrm{r}=.286, \mathrm{p}<.005)$ attachment styles with transactional leadership style, at $\mathrm{p}<.000)$ but a strong positive relation was found for dismissing $(\mathrm{r}$ $=.622, \mathrm{p}<.005)$ attachment style. Preoccupied attachment has no relation with transactional leadership style $\mathrm{r}=$ $-.084, \mathrm{P}<.005$.

The coefficient of determination (R-square) between transactional leadership style, and dismissing attachment style was .3869 meaning, $38.7 \%$ of the variance of transactional leadership style can be explained by dismissing attachment style.

Laissez-faire leadership style had a positive correlation with preoccupied $(r=.126)$ attachment style, but the association was not significant. However, Laissez-faire leadership style had a moderate and positive significant relationship with dismissing $(\mathrm{r}=.488)$ and fearful attachment styles $(\mathrm{r}=.589)$, at $\mathrm{p}<.000$ respectively.. Laissez-faire leadership style also correlated negatively and weakly with secure attachment style $(r=-.146, p<.000)$.

The coefficient of determination (R-square) between laissez-faire leadership style and dismissing and fearful attachment style is .2381 and .3469 respectively, meaning, $23.8 \%$ and $34.7 \%$ of the variance of in laissez-faire leadership can be explained by dismissing and fearful attachment style respectively.

It was also found that there is a negatively weak relationship between teachers perception of their leader effectiveness and preoccupied and dismissing attachment styles $(\mathrm{r}=-152), \mathrm{p}<.005,(\mathrm{r}=-.152) \mathrm{P}<.0005$ respectively. Even though, there is a positive relation between leaders' effectiveness and fearful and secure attachment style, the relationship was very weak $(r=.137), \mathrm{P}<.0005$ and $(r=.231) \mathrm{P}<.0005$. The coefficient of determination (R-square) between leader effectiveness and secure attachment style was .0533 meaning, 5.33\% of the variance of in leaders effectiveness can be explained by secure attachment style.

Table 4: Correlation between attachment styles, leadership styles and perceived principals' effectiveness

\begin{tabular}{llll} 
& $\begin{array}{l}\text { Attachment } \\
\text { style }\end{array}$ & $\begin{array}{l}\text { Leadership } \\
\text { style }\end{array}$ & $\begin{array}{l}\text { Leaders' } \\
\text { effectiveness }\end{array}$ \\
Attachment style & 1 & & \\
Leadership style & $.550^{* *}$ & 1 &. \\
Leaders' effectiveness & $.632^{* *}$ & $.669 * *$ & 1 \\
\hline
\end{tabular}

In addition to seeing the relationship between individual attachment style (secure, preoccupied, dismissing and fearful), different leadership styles (transformational, transactional and laissez-faire) and leaders' effectiveness, the relationship between the aggregate attachment style, leadership style and principals effectiveness was computed. As it was depicted on Table 4 there was positive moderate level of relationship between leadership style and overall attachment styles. On the other hand there was strong correlation between attachment styles and perceived leadership effectiveness $(r=.632), \mathrm{P}<.005$ and similarly strong relationship between leadership style and perceived leadership effectiveness $(\mathrm{r}=.669), \mathrm{P}<.005$.

The coefficient of determination (R-square) between leadership style leaders' effectiveness is .4475, meaning, $44.8 \%$ of the variance of in leadership effectiveness can be explained by leadership style. On the other hand $39.9 \%$ leaders' effectiveness is explained by the attachment style of the leaders.

\section{Regression Analysis}

When there are two or more than two independent variables, the analysis concerning relationship is known as multiple correlations and the equation describing such relationship as the multiple regression equation (Kotari 2004). The following section explains multiple regression taking four independent variables and one dependent 
variable. Table 4 deals with the results of Multiple Regression for different Attachment Styles Predicting Leadership styles and leaders' effectiveness (unstandardized beta, std. error). The analysis was done to see the relationship among different attachment style as they explain variation in leadership styles and leaders' effectiveness as perceived by teachers, the four attachment styles were used as predictors of each leadership style and leaders' effectiveness.

Before conducting correlation analysis the assumptions of normality, homoscedasticity and the absence of multicollinearity were checked. The normal P-p plot was used to assess normality between each leadership and attachment style, which depicts that the data follows the normal line. Thus, the assumption of normality is met. Homoscedasticity also was assessed by a scatter plot of the regression residuals which was used as a function of the predicted values. Since the scatter plot shows a rectangular distribution without any distinguishable pattern, the assumption of homoscedasticity was also met (Pallant, 2007; Kothari 2004). The absence of multicollinearity was assessed by Variant Inflation Factor (VIF), such that any VIF over 10 may indicate an issue of multicollinearity, or high correlation between independent variables. For the multiple linear regressions for this study, none of the VIFs exceeded 1 , so the assumption of absence of multicollinearity was met.

The result of all the dependent variables and the beta coefficients for all the independent variables are shown in Table

Table 5: result for regression analysis

\begin{tabular}{lllll} 
& Transformational & transactional & Laissez-faire & Leader's effectiveness \\
\hline constant & $35.052(4.945)$ & $16.123(3.689)$ & $3.695(1.538)$ & $1.233(.503)$ \\
secure & $4.053(.927)$ & $1.847(.691)$ & $-.566(.288)$ & $.287(.094)$ \\
preoccupied & $1.693(.817)$ & $-1.214(.610)$ & $.052(.254)$ & $.068(.083)$ \\
dismissing & $5.411(.756)$ & $4.269(.564)$ & $1.469(.235)$ & $.498(.077)$ \\
fearful & $-2.641(.782$ & $1.010(.584)$ & $1.528(.243)$ & $-.259(.080)$ \\
F & 32.934 & 30.175 & 41.317 & 21.878 \\
DF & 197 & 197 & 197 & 197 \\
Model R square & .406 & .385 & .461 & .312 \\
\hline
\end{tabular}

Based on the above conditions the results of regression indicated that attachment styles significantly predict leadership styles and leadership effectiveness. The coefficient of determination, $R 2$, suggested that approximately $41 \%$ of the variability in transformational leadership style was predicted by the four independent variables, meaning that the predictors had a little less than half ability to predict the outcome behavior. Similarly, approximately $41 \%$ and $39 \%$ of the transactional and laissez-faire leadership style was predicted by the four attachment styles. The interpretation of $r 2$ is really quite telling. In this example, the result also tells us that variation in level of leadership effectiveness explains $31 \%$ of the variation in the predictor variables or attachment style of the leaders. In everyday terms, variables other than attachment styles determine more the effectiveness of the leadership in the educational institutions.

\section{Discussion}

The study tried to assess the correlation between different attachment style and leadership style and the result revealed there was strong correlation between dismissal attachment style and transactional and laissez-faire leadership style. Fearful attachment behavior of the leader is also moderately correlates with laissez faire leadership style. In every day words this implies those principals who have a difficult time being close and trusting their subordinate, but have a positive view of themselves. This finding was similar to (Bartholomew \& Horowitz, 1991; and Mayseless, Ofra and Popper, 2019). Positive weak relationship was observed between preoccupied and transactional and laissez-faire leadership style. Similarly, positive weak relation was reported between secure attachment style and transformational leadership style. Boatwright et al., (2010); and Choi, (2006) in their study were in support of this finding, they reported that transformational leadership was related to secure attachment style. That means a principal with transformational leadership style are mostly likely to have a trusting and positive relation with teachers.

On the other hands, negative weak relation was found between preoccupied and transactional, fearful and transformational; and secure and laissez-faire respectively. In general, it was reported that dismissing attachment style contribute $22.2 \%$ and secure attachment style contributed $14.4 \%$ for transformational leadership style. Even if, the contribution is not that much strong, dismissing and secure attachment style have some determinant power in transformational leadership style.

This study also showed that there was a significantly moderate relationship between principals' effectiveness and secure attachment style. In other words school principals who have a positive view of themselves and their school teachers; in some cases become effective. Similar results were reported by Bartholomew \& Horowitz, 1991; Griffin \& Bartholomew, 1994; Ross, McKim, \& Ditommaso, (2006), as their results would manifest moderate level of effectiveness. Very weak relationship was observed between fearful attachment style and effectiveness of the principals as perceived by the teachers. 
Consistent with previous research laissez-faire leadership style has positive and strong correlation with dismissal and fearful attachment style. This means that $23.8 \%$ and $34.7 \%$ of the variance of in laissez-faire leadership style can be explained by dismissing and fearful attachment style respectively. This finding was found similar to the result of Boatwright, Lopez, Sauer, VanDerWege, \& Huber, (2010). In addition to correlational analysis, a regression analysis result indicated that the four attachment style statistically significant predictor of leadership styles (transformational, transactional and laissez-faire) even if the predictive power is low.

The aggregate analysis was also done to see the relationship between attachment styles, leadership style and leaders' effectiveness. It was found that there was positive but moderate level of relationship between leadership style and overall attachment styles. On the other hand there was strong correlation between attachment styles and leadership style with perceived leadership effectiveness. On the other hand, The coefficient of determination (Rsquare) between leadership styles and leaders' effectiveness is .4475 , meaning, $44.8 \%$ of the variance of in leadership effectiveness can be explained by leadership style. In similar way $39.9 \%$ leaders' effectiveness is explained by the attachment style of the leaders. In general, this shows that leadership style and attachment styles of the leaders' determine their leadership effectiveness in secondary schools of Hawassa University community service area.

In general, the study was crucial to understand how leaders' attachment style affects their leadership style and their effectiveness in educational institution. My findings are also crucial in gaining a better perspective on the role of attachment style in leadership styles and how leaders' attachment styles and their leadership styles determine leaders' effectiveness. Thus, it is better to train and familiarized principals on who their attachment style and leadership style affect their communication and how to encourage follower to be effective. It is also recommended that future research could do similar study using a different population in different setting, with different leadership style and different type of attachment styles to determine if the findings are reliable.

\section{REFERENCES}

Adegun O.A (2002) Communication and Administrative effectiveness of secondary school Principals in South West Nigerian. Unpublished Ph.D Thesis University Of Ado-Ekiti, Nigeria

Ainsworth, M. D. S., Blehar, M. C., Waters, E., \& Wall, S. (1978). Patterns of attachment: Apsychological study of the strange situation. Hillsdale, $\mathrm{NJ}$ : Erlbaum.

Amneric, J., Craig, R., \& Tourish, D. (2007). The transformational leader as pedagogue,physician, architect, commander, and saint: Five root metaphors in Jack Welch's letters to stockholders of general electric. Human Relations, 60(12), 1839-1872.

Avolio, B.J., Rotundo, M.\& Walumbwa, F. O. (2009). Early life experiences and environmental factors as determinants of leadership emergence: the role of parental influence and rule breaking behavior. The Leadership Quarterly,

Barrick, M., \& Mount, M. (1991). The big five personality dimensions and job performance: A meta-analysis. Personnel Psychology, 44(1), 1-26. Retrieved from http://people.tamu.edu/ mbarrick/Pubs/1991 Barrick Mount.pdf

Bartholomew, K., \& Horowitz, L. M. (1991). Attachment styles among young adults: A test of a four-category model. Journal of Personality and Social Psychology, 61(2), 226-244.

Bass, B. M. (1985). Leadership and performance beyond expectations. New York: The Free Press.

Bass, B. M., \& Avolio, B. J. (2000). Multifactor leadership questionnaire. Redwood City, CA: Mind Garden.

Berson, Y., Dan, O., \& Yammarino, F. J. (2006). Attachment style and individual differences in leadership perceptions and emergence. The Journal of Social Psychology, 146(2),

Boatwright, K. J., Lopez, F. G., Sauer, E. M., VanDerWege, A., \& Huber, D. M. (2010). The influence of adult attachment styles on workers' preferences for relational leadership behaviors. The Psychologist-Manager Journal, 13(1), 1-14.

Bowlby J. (1988) A Secure Base. Clinical Applications of Attachment Theory. Routledge

Breshanan, C., \& I. Mitroff (2007). Leadership and attachment theory. American Psychologist 62: 607-608.

Bretherton, I. (1985). Attachment theory: Retrospect and prospect. In I. Bretherton \& E. Waters (Eds.), Growing points of attachment theory and research (pp. 3-37). Monographs of the Society for Research in Child Development, 50(1-2, Serial No. 209).

Choi, J. (2006). A motivational theory of charismatic leadership: Envisioning, empathy, and empowerment. Journal of Leadership and Organizational Studies, 13(1), 24- 43.

Davidovitz, R., Mikulincer, M., Shaver, P. R, Izsak, R., \& Popper, M. (2007). Leaders as attachment figures: Leaders' attachment orientations predict leadership-related mental representations and followers' performance and mental health. Journal of Personality and Social Psychology, 93(4), 632-650.

De Hoogh, A., Hartog, H. B., \& Koopman, P, L. (2005). Linking the big five- factors of personality to charismatic and transactional leadership: Perceived dynamic work environment as a moderator. Journal of Organizational Behavior, 26(7), 839-865. 
De Sanctis, M., \& Karantzas, G. (2008). The associations between attachment style and leadership behaviours. Paper presented at the 8th Annual Conference of the Australian Psychological Society: Melbourne, Australia.

Doverspike, D., Hollis, L. Justice, A.\& Polomsky, M. (1997). Correlations between leadership styles as measured by the Least Preferred Co-Worker scale and adults' attachment styles. Psychological Reports 81: 1,148-1,150.

Evans, J. D. (1996). Straight forward statistics for the behavioral sciences. Pacific Grove, CA: Brooks/Cole

Fraley, R.C., \& Shaver, P. (2000). Adult romantic attachment: theoretical developments, emerging controversies, and unanswered questions. Review of General Psychology 4: 132-154.

Griffin, D.W., \& Bartholomew, K. (1994). The metaphysics of measurement: the case of adult attachment. In: K. Bartholomew \& D. Perlman (Eds.), Advances in Personal Relationships, volume 5: Attachment Processes in Adulthood (pp. 17-52). London: Jessica Kingsley Publishers.

Johnston, M. (2000). Delegation and organizational structure in small businesses: influence of manager's attachment patterns. Group and Organization Management 25: 4-21.

Keller, T. (2003). Parental images as a guide to leadership sense making: an attachment perspective on implicit leadership theories. Leadership Quarterly 14: 141-160.

Kothari, C.R. (2015) Research methodology: methods and techniques, new age international limited publishers

Manning, T. T. (2003). Leadership across cultures: Attachment style influences. Journal of Leadership and Organizational Studies, 9(3), 20-30.

Mayseless, O., \& Popper, M. (2007). Reliance on leaders and social institutions: an attachment perspective. Attachment and Human Development 9: 73-93.

Mayseless, Ofra \& Popper, M. Micha (2019) Attachment and leadership: review and new insights. Current Opinion in Psychology, 25: 157-161

Mikulincer, M., \& Florian, V. (1995). Appraisal of and coping with a real-life stressful situation: The contribution of attachment styles. Journal of Personality and Social Psychology, 21(4), 406-414.

Northouse, Peter G. (2015) Leadership: Theory and Practice, 7th edition. Sage Publications

Padilla, A., Hogan, R., \& Kaiser, R. B. (2007). The toxic triangle: Destructive leaders, susceptible followers, and conducive environments. The Leadership Quarterly, 18(3),176-194.

Pallant, J. (2007). SPSS Survival Manual (3rd ed.). Berkshire, England: Open University Press.

Popa, Brindusa Maria (2012). The relationship between leadership Effectiveness and organizational

Performance, Journal of defense resource management, Vol 3(1)

Popper, M., \& Mayseless, O. (2003). Back to basics: Applying a parenting perspective to transformational leadership. Leadership Quarterly, 14(2003), 41-65.

Popper, M., Mayseless, O.\& O. Castlenovo (2000). Transformational leadership and attachment. Leadership Quarterly 11: 267-289.

Ronen, S., \& Mikulincer, M. (2010). Predicting employee's satisfaction and burnout from managers' attachment and caregiving. Paper presented at the Annual Meeting of the Academy of Management, Montreal, Canada.

Sadeghi, A., \& Lope Pihie, Z. A. (2012). Transformational leadership and its predictive effects on leadership effectiveness. International Journal of Business and Social Science, 3(7), 186-193. Retrieved at www.ijbssnet.com

Skogstad, A., Einarsen, S., Torsheim, T., Aasland, M. S., \& Heland, H. (2007). The destructiveness of laissezfaire leadership behavior. Journal of Occupational Health Psychology, 12(1), 80-92.

Tabachnick, B. G. \& Fidell, L. S. (2007). Using multivariate statistics (5th ed.). MA: Allyn and Bacon.

Tepper, B. (2000). Consequences of abusive supervision. Academy of Management Journal, 42(2), 100-108.

Tess S.M Hayble (2003) Personnel Administration towards optimum productivity. Ibadan Awemark industrial printers

Towler, A. (2005). Charismatic leadership development: role of parental attachment style and parental psychological control. Journal of Leadership and Organizational Studies 11: 15-25.

Welch, R. D., \& Houser, M. E. (2010). Extending the four-category model of adult attachment: An interpersonal model of friendship attachment. Journal of Social and Personal Relationships, 27(3), 352-364

Yamane, T. (1967). Statistics: an introductory analysis, $2^{\text {nd }}$ ed. New York: Harper and Row.

Morgan, G. A. (2004). SPSS for introductory statistics: Use and interpretation. Mahwah, NJ: Lawrence Erlbaum Associates 